\title{
Synthesis of $\mathrm{YNi}_{2} \mathrm{~B}_{2} \mathrm{C}$ thin films by magnetron sputtering
}

\author{
Shunichi Arisawa, Takeshi Hatano, Kazuto Hirata, Takashi Mochiku, \\ Hitoshi Kitaguchi, Hiroki Fujii, Hiroaki Kumakura, Kazuo Kadowaki, Keikichi Nakamura \\ and Kazumasa Togano \\ National Research Institute for Metals, 1-2-1, Sengen, Tsukuba 305, Japan
}

(Received 16 May 1994; accepted for publication 24 June 1994)

\begin{abstract}
Thin films of $\mathrm{YNi}_{2} \mathrm{~B}_{2} \mathrm{C}$ superconductor by the magnetron sputtering technique have been synthesized. The $\mathrm{YNi}_{2} \mathrm{~B}_{2} \mathrm{C}$ phase was found to crystallize very uniformly after annealing at $1050^{\circ} \mathrm{C}$ in vacuum. The structure was investigated and the electric and magnetic properties were characterized. The films were $c$-axis oriented and showed a $T_{c}$ onset of $\sim 15 \mathrm{~K}$ by both magnetization and resistivity measurements. The results of the critical current measurement suggested the existence of anisotropies of pinning force and an upper critical ficld $B_{c_{2}}$.
\end{abstract}

Recently, a series of new quaternary superconductors of intermetallic compounds $\mathrm{RE}-\mathrm{T}-\mathrm{B}-\mathrm{C}$ where $\mathrm{RE}=$ rare earth elements, $\mathrm{T}=\mathrm{Ni}, \mathrm{Pd}, \mathrm{Pt}$, have been reported..$^{1-5}$ According to this literature, the crystal structure of these systems has been identified by the $\mathrm{X}$-ray study of $\mathrm{Y}-\mathrm{Ni}-\mathrm{B}-\mathrm{C}$ compound to be the stoichiometric 1221 structure. ${ }^{3}$ Synthesis of thin films of the system, however, has not been reported so far. In this letter, the fabrication method and characterization of $\mathrm{YNi}_{2} \mathrm{~B}_{2} \mathrm{C}$ thin films prepared by the magnetron sputtering technique is reported on.

The target was prepared by arc melting, $99.9 \% \mathrm{Y}$ (ingot), 99.9\% Ni(shot), $99.9 \% \mathrm{~B}$ (flake), and $99.9 \% \mathrm{C}$ (sheet) were melted together under an Ar atmosphere on a water cooled copper hearth using a nonconsumable tungsten electrode. The prepared button was then milled into powder. We used a conventional if magnetron sputtering apparatus with a 4 in. target. The powder was put on the cathode and used as the target. The sputtered material was deposited on $\mathrm{MgO}$ (100) substrates maintained at room temperature under a pressure of $0.5 \mathrm{~Pa}$ of Ar. The base pressure was $2 \times 10^{-3} \mathrm{~Pa}$. The substrates were arranged in on-axis geometry to the target. The deposition rate was approximately $0.08 \mathrm{~nm} / \mathrm{s}$ and the total thickness of the films was $300 \mathrm{~nm}$.

The sample was then wrapped in a titanium foil and annealed in a vacuum furnace at several temperatures up to $1050^{\circ} \mathrm{C}$ for $20 \mathrm{~min}$. The residual pressure was less than $7 \times 10^{-4} \mathrm{~Pa}$. The composition ratio of $\mathrm{Y}$ and $\mathrm{Ni}$ was confirmed to be 1:2 within the error of our energy dispersive $x$-ray analyzer (EDAX). Because of the small atomic weights of $\mathrm{B}$ and $\mathrm{C}$, we were not able to determine their concentrations.

The scanning electron microscope (SEM) image of the cross section of the cleaved sample is shown in Fig. 1. This figure indicates that the film has uniform texture on the $\mathrm{MgO}$ substrate. Since the cleaved edge was very sharp, the film thickness was determined by the SEM observation to be approximately $0.3 \mu \mathrm{m}$. It was difficult to observe the microstructure such as grain structure inside the film by the SEM.

The crystal structure of the films was investigated by an $\mathrm{x}$-ray diffractometer $(\theta-2 \theta$ scan) using a $\mathrm{Cu}$ target. The asdeposited films were completely amorphous as evidenced by a single broad peak around $2 \theta \approx 22^{\circ}$. Below the annealing temperature of $900^{\circ} \mathrm{C}$ only very weak reflections, which could not be identified as the $\mathrm{YNi}_{2} \mathrm{~B}_{2} \mathrm{C}$ phase, were observed in the diffraction pattern. In contrast to this, the film transformed into a crystalline form after annealing at $1050^{\circ} \mathrm{C}$ seen in the diffraction pattern presented in Fig. 2. The two sharp peaks can be indexed as (002) and (004) reflections of $\mathrm{YNi}_{2} \mathrm{~B}_{2} \mathrm{C}$ structure, indicating that the film has a strong $c$-axis orientation. Several reflections from the other planes were also observed.

Superconductivity was investigated by both dc magnetization measurement using a superconducting quantum interference device (SQUID) magnetometer of Quantum Design and resistivity measurement using a conventional four-probe technique.

The as-deposited sample and those annealed at temperatures below $900^{\circ} \mathrm{C}$ showed no trace of superconductivity. However, the sample annealed at $1050^{\circ} \mathrm{C}$ showed a sharp superconducting transition of $\mathrm{YNi}_{2} \mathrm{~B}_{2} \mathrm{C}$. Figure 3 showed the temperature dependence of the magnetization measured in a field of $5 \mathrm{G}$ applied perpendicular to the film surface. The curve showed a sharp transition with the onset of $15 \mathrm{~K}$, which was almost the same as the value reported for bulk sample by Cava et $a l^{2}$ A much larger signal for zero-field cooling (ZFC) than field cooling (FC) was considered to be caused by the demagnetizing effect. The measurement in par-

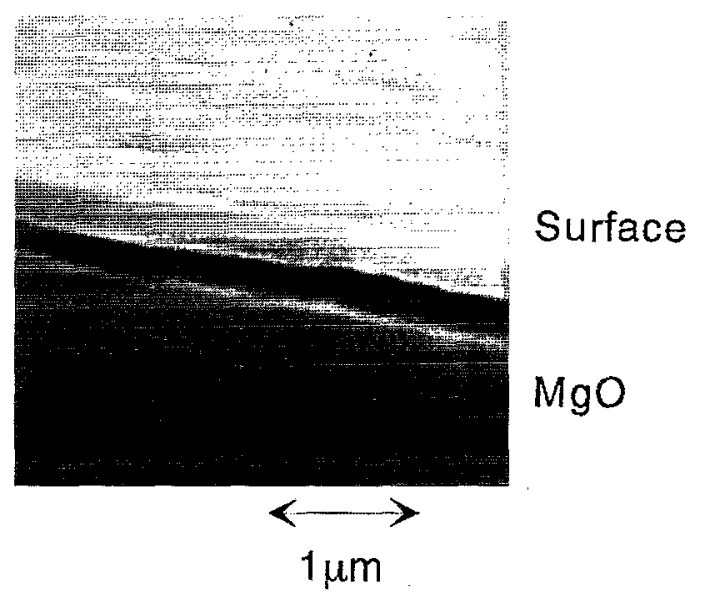

FIG. 1. Cross sectional SEM image of the annealed sample. 


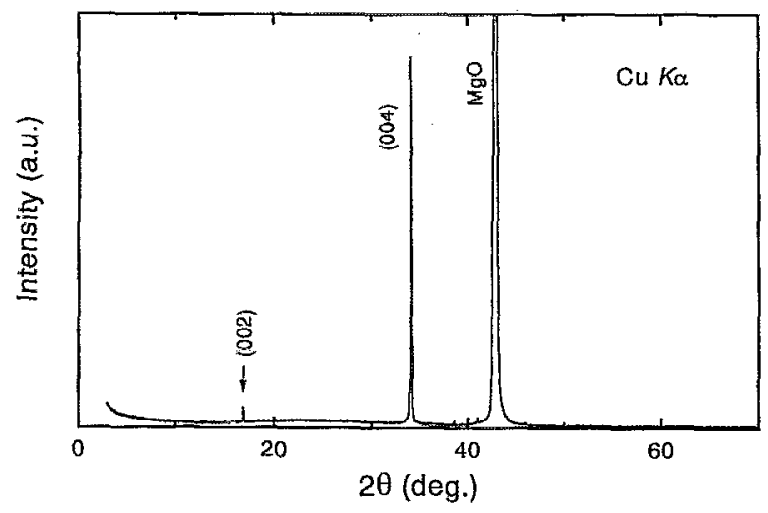

FIG. 2. X-ray diffraction pattern of the annealed sample of the $\mathrm{YNi}_{2} \mathrm{~B}_{2} \mathrm{C}$ thin film.

allel field to the film surface resulted in a much smaller difference in magnetization between FC and ZFC.

Figure 4 shows the temperature dependence of the inplane resistivity. The sharp drop of the resistivity is observed at $15 \mathrm{~K}$. This temperature $T_{c}$ is in good agreement with that of the transition in magnetization in Fig. 3. The resistivity just above $T_{c}$ is approximately $40 \mu \Omega \mathrm{cm}$, which is a rather high value compared to the value of the bulk sample. ${ }^{2}$ The resistivity ratio at just above $T_{c}$ to that at room temperature is about 1:6, which is also larger than the bulk value. There are two possible causes for the higher resistivity of the film: one is the existence of defects including grain boundaries introduced during the film synthesis, the other is the size effect which occurs when the film thickness is smaller than the mean free path (m.f.p.) of carrier electrons. However, the latter is not plausible in this case if the m.f.p. of the material

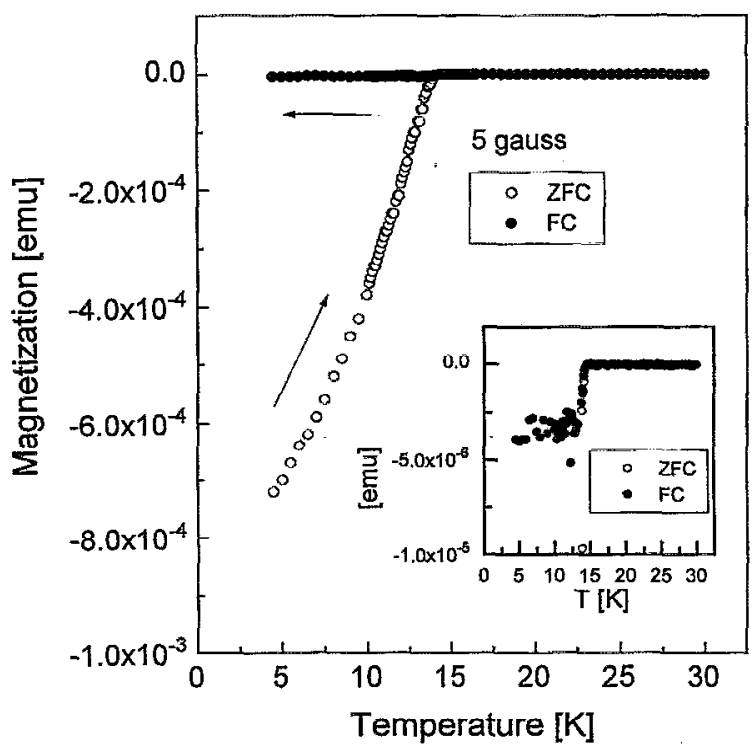

FIG. 3. Temperature dependence of the magnetization of the $\mathrm{Y}-\mathrm{Ni}-\mathrm{B}-\mathrm{C}$ thin film measured in a magnetic field of $5 \mathrm{G}$ perpendicular to the film plane. The arrows represent warming process after cooling in zero field, and cooling process in the field. Inset shows the expanded view of the field cool data.

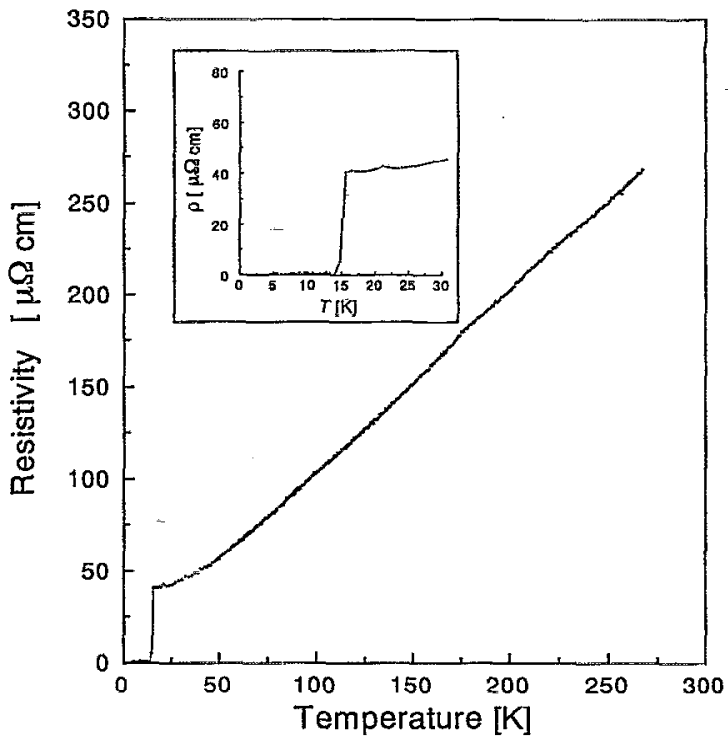

FIG. 4. Temperature dependence of the in-plane resistivity between 4.2 and $270 \mathrm{~K}$ for the annealed sample of $\mathrm{YNi}_{2} \mathrm{~B}_{2} \mathrm{C}$ thin film.

is the samc order or less than that of typical metal.

The critical current densities of the film were measured at $4.2 \mathrm{~K}$ in applied magnetic fields by a superconducting magnet for the two pieces of the sample, $\mathrm{A}$ and $\mathrm{B}$, which were cut out into the rectangular shape from the same sample annealed at $1050^{\circ} \mathrm{C}$. The magnetic field was applied parallel to the film surface (perpendicular to the $c$ axis: $B_{\perp c}$ ) for sample $A$ and perpendicular (parallel to the $c$ axis: $B_{\| c}$ ) to the film surface for the sample $B$, respectively. The current flow was perpendicular to the ficld for both samples. The critical current, $I_{c}$, was defined by a sharp rise in voltage across the $4 \mathrm{~mm}$ gauge length and the critical current density $I_{c}$ was calculated by dividing $I_{c}$ by the cross sectional area of the film. The $J_{c}$ of sample A is 2-3 times larger than that of

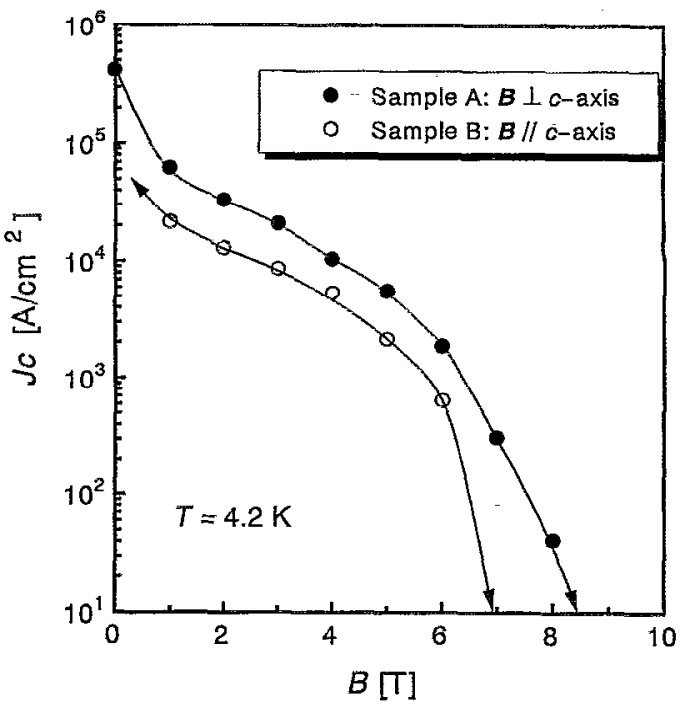

FIG. 5. The field dependence of the critical currents of $\mathrm{YNi}_{2} \mathrm{~B}_{2} \mathrm{C}$ thin film. 
sample $\mathrm{B}$ in fields up to $\sim 6 \mathrm{~T}$, suggesting a stronger pinning force in the field parallel to the film surface. At $7 \mathrm{~T}$, the $J_{c}$ curve of sample B occurred rapidly below the detection limit in our measurements, while sample A maintained appreciable values even up to $8 \mathrm{~T}$. This large difference in $J_{c}$ characteristics at higher magnetic field suggest that the material has an anisotropy in the upper critical field, $B_{c_{2}}$. The difference of $B_{c_{2}}$ (at $4.2 \mathrm{~K}$ ) between $B_{\| c}$ and $B_{\perp c}$ estimated from Fig. 5 is about $1.5 \mathrm{~T}$.

We have successfully synthesized thin films of $\mathrm{YNi}_{2} \mathrm{~B}_{2} \mathrm{C}$ by the magnetron sputtering technique. By post annealing at $1050^{\circ} \mathrm{C}$, the film is found to transform to the crystalline $\mathrm{YNi}_{2} \mathrm{~B}_{2} \mathrm{C}$ phase from the amorphous phase. The obtained film was highly $c$-axis oriented and showed a superconducting transition at $15 \mathrm{~K}$. The results of critical current measurement indicate the anisotropies of pinning force and upper critical field $B_{c_{2}}$.
The authors would like to thank W. H. Soe for his technical advice and Professor R. Yamamoto of the University of Tokyo for his continuous encouragement in this work. The authors are also grateful to Dr. M. Fukutomi, Dr. H. Takeya, and $\mathrm{K}$. Komori of the National Research Institute for Metals for a fruitful and informative discussion.

${ }^{1}$ R. Nagarajan, C. Mazumdar, Z. Hossain, S. K. Dhar, K. V. Gopalalkrishnan, L. C. Gupta, C. Godart, B. D. Padalia, and R. Vijayaraghavan, Phys. Rev. Lett. 72, 274 (1994).

${ }^{2}$ R. J. Cava, H. Takagi, H. W. Zandbergen, J. J. Krajewski, W. F. Peck, Jr., T. Sieglist, B. Batlogg, R. B. van Dover, R. J. Felder, K. Mizuhashi, J. O. Lee, H. Eisaki, and S. Uchida, Nature 367, 252 (1994).

${ }^{3}$ T. Siegrist, H. W. Zandbergen, R. J. Cava, J. J. Krajewski, and W. F. Peck, Jr., Nature 367, 254 (1994).

${ }^{4}$ H. Fujii, S. Ikeda, T. Kimura, S. Arisawa, K. Hirata, H. Kumakura, K. Kadowaki, and K. Togano, Jpn. J. Appl. Phys. 33, L590 (1994).

${ }^{5}$ R. J. Cava, H. Takagi, B. Batlogg; H. W. Zandbergen, J. J. Krajewski, W. F. Peck, Jr., R. B. van Dover, R. J. Felder, T. Sieglist, K. Mizuhashi, J. O. Lee, H. Eisaki, S. A. Carter, and S. Uchida, Nature 367, 146 (1994). 